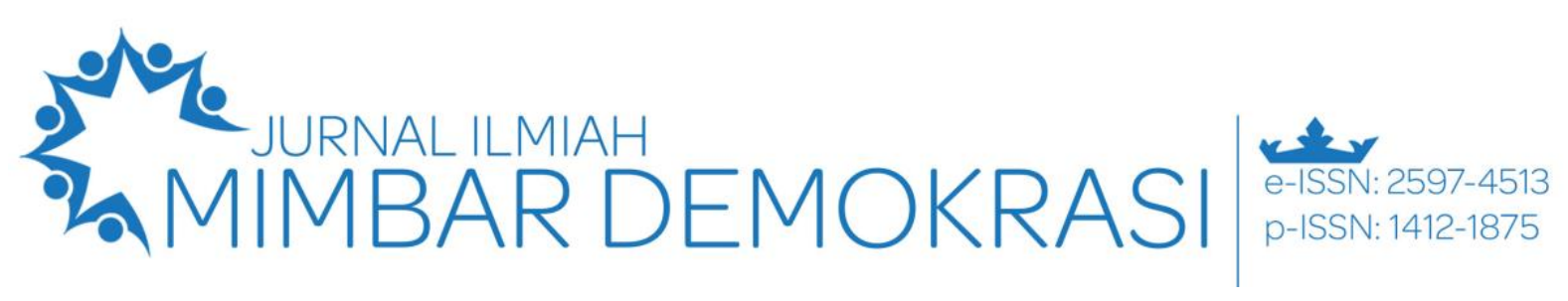

Vol. 20 No. 1 Tahun 2020 | Hal. 1 - 10

\title{
Nilai budaya masyarakat Sulawesi Utara sebagai model pendidikan toleransi
}

\author{
Theodorus Pangalila ${ }^{a},{ }^{*}$, Jeane Mantirib ${ }^{2}$ \\ a Jurusan PPKn FIS Universita Negeri Manado, Tondano Sulawesi Utara \\ b Prodi Ilmu Administrasi Negara FIS Universitas Negeri Manado, Tondano Sulawesi Utara \\ 1 theopangalila@unima.ac.id; jeanemantiri@unima.ac.id \\ *korespondensi penulis
}

\begin{tabular}{l}
\hline Informasi artikel \\
Diterima: \\
4 Juli 2020 \\
Disetujui: \\
26 September 2020
\end{tabular}

Kata kunci:

Nilai

Budaya

Masyarakat

Pendidikan toleransi

\begin{abstract}
ABSTRAK tercermin dari semboyan bangsa Indonesia: Bhinneka Tunggal Ika. Kenyataan dewasa ini menunjukkan banyaknya kasus intoleransi terus terjadi. Di tengah banyaknya kasus Intoleransi di berbagai daerah di Indonesia, kenyataan membuktikan bahwa masyarakat kota Tomohon-Sulawesi Utara tetap hidup dalam suasana penuh toleransi di tengah perbedaan agama, suku, ras, bahasa dan budaya. Tujuan penelitian ini adalah mendeskripsikan tentang bagaimana nilai-nilai kearifan lokal masyarakat Sulawesi Utara menjadi model toleransi. Penelitian ini dilakukan di kota Tomohon Sulawesi Utara. Sumber data dalam penelitian ini adalah masyarakat lokal, berbeda agama, suku, bahasa, pemuka agama dan pemerintah. Penelitian ini menggunakan pendekatan deskriptif kualitatif dengan pengumpulan data melalui observasi, wawancara dan studi dokumentasi. Adapun penelitian ini menemukan bahwa nilai budaya/kearifan lokal masyarakat Sulawesi Utara: Si Tou Timon Tumon Tou (Manusia Hidup untuk Memanusiakan Orang Lain), Mapalus (Gotong-royong) dan Torang Samua Basudara (Kita Semua Bersaudara) mampu membuat masyarakat Sulawesi Utara hidup dalam suasana penuh toleransi, sehingga bisa diadopsi dan dikembangkan menjadi model pendidikan toleransi. Ketiga nilai budaya ini terimplementasi secara konkrit dalam kehidupan konkrit masyarakat yang tidak membeda-bedakan asal-usul suku, agama, etnis dari masyarakat. Adapun penelitian ini merekomendasikan penelitian lanjut tentang pengembangan model pembelajan berbasis nilai budaya lokal.
\end{abstract}

\section{Received: \\ 4 July 2020 \\ Accepted: \\ 26 Sept 2020}

Keywords:

Values

Culture

Society

Tolerance education

\begin{abstract}
The Cultural Values of North Sulawesi People as a Model of Tolerance Education. The basic nature of the Indonesian people is a plural and multicultural nation. This is reflected in the Indonesian motto: Unity in Diversity. Today's reality shows that many cases of intolerance continue to occur. In the midst of the many cases of intolerance in various regions in Indonesia, the reality proves that the people of the city of Tomohon-North Sulawesi continue to live in an atmosphere of tolerance in the midst of differences in religion, ethnicity, race, language and culture. The purpose of this study is to describe how the values of the local wisdom of the people of North Sulawesi become a model of tolerance. This research was conducted in the city of Tomohon, North Sulawesi. The data sources in this study are local people, different religions, ethnicities, languages, religious leaders and government. This research uses a qualitative descriptive approach by collecting data through observation, interviews and documentation studies. The research found that the cultural values / local wisdom of the North Sulawesi people: Si Tou Timon Tumou Tou (Humans Live to Humanize Others), Mapalus (Mutual Cooperation) and Torang Samua Basudara (We Are All Brothers) are able to make North Sulawesi people live in an atmosphere of tolerance, so that it can be adopted and developed into a model of tolerance education. These three cultural values are implemented concretely in the concrete life of the community which does not differentiate between ethnic, religious, and ethnic origins from the community. The study recommends further research on the development of a learning model based on local cultural values.
\end{abstract}

Copyright $(\mathcal{O} 2020$ (Theodorus Pangalila \&Jeane Mantiri). All Right Reserved 
How to Cite: Pangalila, T. \& Mantiri, J. (2020). Nilai budaya masyarakat Sulawesi Utara sebagai model pendidikan toleransi. Jurnal Ilmiah Mimbar Demokrasi, 20(1), 1-10. DOI: 10.21009/jimd.v20i01.15924

This work is licensed under a Creative Commons Attribution-Share Alike 4.0 International License. Allows readers to read, download, copy, distribute, print, search, or link to the full texts of its articles and allow readers to use them for any other lanful purpose. The journal bold the copyright.

\section{Pendahuluan}

Indonesia adalah negara kepulauan terbesar di dunia (Latief, 2017). Sebagai negara kepulauan Indonesia terdiri dari 17.508 pulau dan 1.128 suku bangsa. Keanekaragaman suku, budaya, agama, ras dan tata berperilaku masyarakat mencari ciri khas tersendiri bagi bangsa Indonesia (Pangalila, Mantiri, \& Umar, 2019; Pangalila, Ngarawula, Sadhana, Lonto, \& Pasandaran, 2018). Bukti eksistensi keberagaman di Indonesia sangat nyata dalam Semboyan bangsa Indonesia: Bhinneka Tunggal Ika. Frasa ini berasal dari bahasa Jawa Kuno dan seringkali diterjemahkan dengan kalimat "Berbeda-beda tetapi tetap satu." Indonesia ditinjau dari aspek manapun merupakan sebuah bangsa yang majemuk. Kemajemukan ini tampak dalam manifestasi kebudayaan bangsa Indonesia yang tidak "satu." Kemajemukan sosial dan budaya Indonesia ditandai dengan banyaknya budaya dan agama di Indonesia. Sebagai contoh budaya Jawa, Sunda, Minahasa, Batak, dan lainlain. Dari segi agama di Indonesia terdapat enam agama yang diakui secara resmi oleh pemerintah: Islam, Kristen Protestan, Katolik, Hindu, Budha dan Konghucu (Pangalila, Ngarawula, \& Sadhana, 2018; Pangalila, Ngarawula, Sadhana, et al., 2018).

Tingginya pluralisme bangsa Indonesia membuat potensi konflik bangsa Indonesia juga tinggi. Potensi perpecahan dan kesalahpahaman juga tinggi, baik konflik dalam skala kecil maupun besar (Syahid \& Daulay, 2002). Dalam skala kecil, konflik tercermin pada komunikasi yang tidak tersambung atau tidak berjalan sebagaimana mestinya, sehingga menyebabkan rasa tersinggung, marah, frustasi, kecewa, dongkol, bingung, bertanya-tanya, sementara itu konflik dalam skala besar mewujud dalam, misalnya kerusuhan sosial, kekacauan multi budaya, perseteruan antar ras, etnis, dan agama (DM \& Rijal, 2018).

Tak bisa dipungkiri, Indonesia memang merupakan suatu bangsa yang terdiri atas berbagai kebudayaan dan adat-istiadat. Sayangnya, implementasi proses kehidupan bermasyarakat di tengah perbedaan dan keanekaragaman ini (suku bangsa, budaya, ras, agama, dan sejenisnya) tidaklah semudah apa yang dipikirkan. Pergeseran antar kelompok agama maupun suku, budaya ataupun adat istiadat yang berbeda seolah menjadi pemicu terjadinya suatu perpecahan horizontal antar masyarakat yang berlainan tersebut. Sejak tahun 1997 negara kita dilanda berbagai macam konflik. Konflik terjadi di berbagai daerah di Indonesia, misalnya di Ambon, Papua, Kalimantan, Posso, dan di daerah-daerah lain di Indonesia. Konflik antar golongan dalam masyarakat seakan-akan tak terelakkan lagi di berbagai daerah di negara kita ini. Dengan adanya konflik ini banyak orang dibunuh dan saling membunuh; banyak orang kehilangan tempat tinggal karena dirusak massa, ada pula yang mengungsi ke pulau-pulau lain (Pangalila, 2018). Selama 2019 terdapat 31 kasus intoleransi atau pelanggaran kebebasan beragama dan berkeyakinan di Indonesia. Sejumlah 28 kasus di antaranya dilakukan oleh warga setempat yang dimobilisasi oleh organisasi atau kelompok agama tertentu (Sutiawan, 2019).

Bahkan di era perjuangan kemerdekaan hingga akhirnya Indonesia dapat meraih kemerdekaan secara mandiri, dikarenakan semangat toleran para pejuang kemerdekaan dengan menanggalkan egoistis suku, ras, serta agama, yang menimbulkan semangat persatuan dan kesatuan seluruh masyarakat Indonesia untuk mengusir para penjajah dari Bumi Pertiwi. Semangat toleransi yang dibalut dengan rasa nasionalisme dan rasa cinta tanah air hingga saat ini masih dijunjung tinggi dalam mengisi kemerdekaan Indonesia.

Semangat toleransi dan keberagaman sebenarnya telah menjadi spirit masyarakat sebelum Indonesia merdeka. Bukti dari dari toleransi ini terlihat dalam mencapai kemerdekaan yang dipelopori dan diusahakan oleh semua suku, agama, ras, dan antar golongan (SARA) pada saat itu (Waruwu \& Pramono, 2018).

Toleransi adalah elemen penting dari komunikasi antar budaya; kemampuan untuk memahami hal yang penting tidak hanya dalam diri sendiri, tetapi dalam budaya yang berbeda, untuk melihat nilai dimulai dari yang lain, kepercayaan orang lain, untuk menghindarkan alasan yang tidak bertentangan dengan nilai-nilai spiritual dan moral (Juwita, Salim, \& Winarno, 2018). Lebih lanjut ditekankan bahwa toleransi berasal dari bahasa Latin tolerare yang berarti menahan diri, sabar, membiarkan orang lain berpikir secara berbeda, berhati terbuka dan toleran terhadap orang-orang 
Timou Tumou Tou, Mapalus dan Torang Samua Basudara. Bahkan di Sulawesi Utara ada satu lembaga yang berperan untuk menjaga kerukunan antar agama, yaitu: BKSAUA (Badan Kerja Sama Antar Umat Beragama). Kedua budaya ini dalam perkembangannya dikombinasikan menjadi semboyan masyarakat Sulawesi Utara Torang Samua Basudara (kita semua bersaudara). Semboyan ini dengan jelas menggambarkan bagaimana masyarakat Sulawesi Utara hidup dalam suasana harmonis, penuh persaudaraan.

Dari latar belakang di atas, maka dalam penelitian ini peneliti secara khusus meneliti tentang: "Nilai Budaya Masyarakat TomohonSulawesi Utara sebagai Model Pendidikan.”

\section{Metode}

Dalam penelitian ini, digunakan pendekatan deskriptif kualitatif (qualitative approach). Fokus utama dalam penelitian ini adalah untuk mengungkap bagaimana nilai busaya masyarakat tomohon sebagai model pendidikan toleransi. Penelitian ini dilaksanakan di Kota TomohonSulawesi Utara. Kota Tomohon adalah salah satu kota dari 15 Kabupaten-Kota di Sulawesi Utara. Alasan pemilihan kota Tomohon sebagai lokasi penelitian karena kota Tomohon terkenal sebagai kota yang penuh toleransi. Mayoritas masyarakat kota Tomohon berasal dari suku Minahasa dan beragama Kristen, tetapi dalam kehidupan kongkrit bisa hidup damai dan berdampingan dengan masyarakat pendatang yang mayoritas berasal dari pulau Jawa dan beragam Islam. Instrumen utama adalah peneliti sendiri (key) instrument) dengan menggunakan teknik berfikir analisis untuk mampu membuat/menarik kesimpulan/verifikasi terhadap fenomena yang diteliti (Moleong, 2011). Adapun yang menjadi informan kunci dalam penelitian ini adalah: pemerintah setempat, pemuka agama, forum kerukunan antar umat beragama, pimpinan adat, tokoh-tokoh masyarakat dan masyarakat lokal dan pendatang. Instrumen bantu adalah sarana-sarana atau alat-alat yang dapat membantu penelitian (key) instrument) dalam menarik kesimpulan atau membuat verifikasi terhadap fenomena yang diteliti. Teknik pengumpulan data yang digunakan oleh peneliti dalam penelitian ini ialah: Observasi, Wawancara, Dokumentasi, dan studi literatur. Pengujian keabsahan data, peneliti menggunakan validitas interbal (credibility) pada aspek nilai kebenaran, pada penerapannya ditinjau dari validitas eksternal (transferability), dan realibilitas (dependability) pada aspek konsistensi, serta obyektivitas (confirmability) pada aspek naturalis.

\section{Hasil dan pembahasan}

Nilai budaya dominan di Sulawesi Utara yang bisa dijadikan sebagai sumber pengembangan pendidikan toleransi adalah sebagai berikut:

\section{Nilai budaya Si Tou Timou Tumou Tou}

Nilai budaya Si Tou Timon Tumon Ton merupakan sebuah kepercayaan, konsep dan ide yang menjadi pegangan dalam membuat pilihan ketika hendak berpikir serta bertindak mengenai sesuatu yang tidak pantas dan pantas dilakukan (Tilaar, 1998). Nilai yang terkandung dalam budaya Si Tou Timou Tumou Tou telah mendorong seluruh masyarakat Sulawesi Utara untuk bersikap toleran terhadap orang yang berbeda latar belakang agama, suku, ras, budaya, dan bahasa (Pangalila \& Mantiri, 2019).

Nilai budaya Si Tou Timou Tumou Tou artinya dalam kehidupan setiap hari hakikat hidup manusia adalah proses memanusiakan orang lain menjadi manusia yang seutuhnya. Budaya ini merupakan ungkapan filosofis orang Minahasa terutama sejak Kekristenan masuk ke Tanah Minahasa, kemudian secara intelektual diangkat kembali oleh Sam Ratulangi (Tilaar, 1998). Berdasarkan hasil wawancara terungkap bahwa ungkapan Si Tou Timou Tumou Tou memang ungkapan ini tercermin dari ciri hidup orang-orang Tomohon terbuka dan bergaul tanpa membedabedakan latar belakang suku dan agama orang lain. Dari segi historis ungkapan ini merupakan filosofi masyarakat Minahasa dan menjadi kearifan lokal masyarakat Sulawesi Utara pada umumnya. Wisdom atau kearifan merupakan sebuah pemberian arti secara kolektif, kebijaksanaan dan pengetahuan yang ada pengaruhnya terhadap penanggulangan masalah dalam kehidupan dan mempengaruhi suatu keputusan penyelesaian. Jadi intinya kearifan di sini adalah pengejawantahan unsur pengetahuan dan pemahaman suatu kelompok masyarakat yang mengalami proses perkembangan, dimana komunitas atau kelompok masyarakat ini melalui interaksi yang lama terhimpun sebagai akibat dari proses dan pengalaman panjang dan di dalamnya ada sebuah sistem bahkan ada ikatan hubungan yang bersifat mutualisme (Marfai, 2012). Oleh karena itu sebagai suatu kearifan lokal ungkapan ini telah menjadi landasan berpikir orang Tomohon dan orang Minahasa pada umumnya. Sejak kecil anak-anak sudah dididik dan menjiwai ungkapan Si Tou Timou Tumou Tou ini dan hal ini terbawa terus sampai mereka besar. Dan dalam arti 


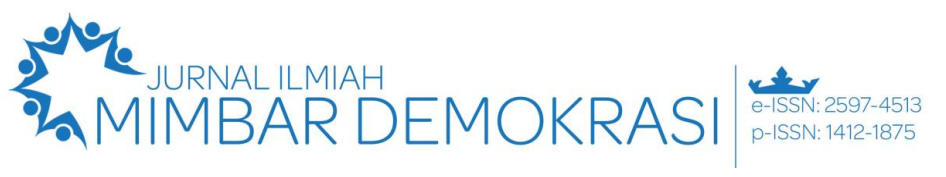

\section{Vol. 20 No. 1 Tahun 2020 | Hal. 55 - 64}

tertentu ungkapan ini "muntep"/mendarah daging dalam kehidupan masyarakat kota Tomohon dan masyarakat Minahasa pada umumnya.

Berdasarkan penuturan para narasumber terungkap bahwa Si Tou Timou Tumou Tou oleh masyarakat Minahasa serta Tomohon pada khususnya dipandang sebagai suatu kepercayaan, ide dan konsep mengenai apa yang layak dan tidak layak dilakukan dalam kehidupannya. Si Tou Timon Tumou Tou di dalamnya mengandung nilai dasar yang telah mendorong masyarakat Tomohon untuk bersikap toleran terhadap orang yang berbeda latar belakang agama, suku, ras, budaya, dan bahasa. Pembahasan dalam artikel bertujuan untuk: (1) menjawab rumusan masalah dan pertanyaan-pertanyaan penelitian; menunjukkan bagaimana temuan-temuan tersebut diperoleh; (3) menginterpretasikan/ menafsirkan temuan-temuan yang diperoleh; (4) mengaitkan hasil temuan penelitian dengan struktur pengetahuan yang telah mapan; dan (5) memunculkan teori-teori baru atau modifikasi teori yang telah ada.

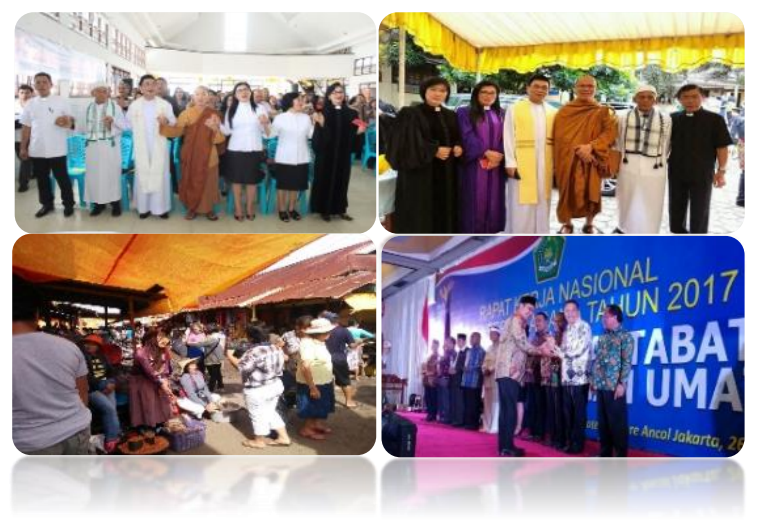

Gambar 1. Wujud Toleransi Masyarakat Kota Tomohon Sulawesi Utara

Temuan penelitian ini mempertegas pendapat Geertz (1975) yang mengatakan bahwa budaya adalah: "an historically transmitted pattern of meanings embodied in symbols, a system of inherited conceptions expressed in symbolic forms by means of which men communicate, perpetuate, and develop their knowledge about and their attitudes toward life" (Geertz, 1975). Geertz menjelaskan bahwa budaya adalah "Pola transmisi historis dari arti yang termasuk dalam simbol-simbol, atau sebuah sistem konsepsi yang disajikan dan diwariskan di dalam cara manusia berkomunikasi, yaitu dalam bentuk simbolsimbol, mengembangkan dan melestarikan pengetahuan yang mereka miliki dan bagaimana mereka menyikapi kehidupannya." Berdasarkan definisinya tentang budaya, Geertz mau menegaskan bahwa budaya adalah suatu dimensi yang aktif dan konstitutif dari kehidupan sosial daripada sekedar mekanisme penjamin integrasi sosial. Geertz melihat budaya sebagai "lengkung simbolis" atau "blueprint" yang dengannya seseorang bisa menciptakan dunia mereka yang bermakna dalam dua level sekaligus: emosi dan kognitif (Sutrisno \& Putranto, 2005).

\section{Nilai budaya Mapalus}

Mapalus merupakan budaya dominan masyarakat Sulawesi Utara. Mapalus dalam arti yang sederhana berarti bentuk kerjasama atau gotong royong dalam mengerjakan suatu pekerjaan (Pangalila, Mantiri, \& Umar, 2019; Salaki, 2014). Istilah Mapalus itu sendiri merupakan gabungan dari kata $m a$ (saling) dan palus (tuang, tumpah). Jadi secara etimologis Mapalus berarti saling menumpah atau saling menuang. Konsep "Si Tou Timou Tumou Tou" dalam kenyataan hidup insan Minahasa/Sulawesi Utara, sejak semula telah tumbuh dan berkembang dalam wujud etos kerja Mapalus atau Maendo (Bahasa Tountemboan) (J. Turang, 1984; T. I. Turang, Suman, Mandang, \& Soemarno, 2012). Dalam konteks ini Mapalus bisa dipandang merupakan suatu bentuk aktualisasi terkonkret mengenai arti terdalam dari "Si Tou Timou Tumou Tou." Nilai budaya Mapalus dalam praktiknya secara jelas dapat dilihat dari empat asas aktualisasinya, yaitu musyawarah dan mufakat, kekeluargaan, keagamaan dan kerjasama), serta lima aspek dalam pengornisasian prinsip hidup Mapalus, yaitu: keterbukaan, tolong-menolong, kebersamaan, disiplin kelompok, dan hasil daya guna (Umbas, 2011). Budaya Mapalus ini sering saya dengar. Mapalus itu seperti gotong royong atau saling membantu satu sama lain. Nilai Mapalus di sini diterapkan dengan baik, dan menyebabkan jiwa saling membantu itu tertanam betul pada masyarakat Tomohon. Mapalus sangat berpengaruh terhadap cara pikir dan bertindak masyarakat kota Tomohon bahkan sudah mengakar dan mendarah daging yang terwujud dalam kegiatan-kegiatan sosial seperti kerukunan kampung, kerukunan semarga, dan lain-lain. Nilai budaya Mapalus ini dalam budaya orang Minahasa 
Mapalus merupakan suatu hal yang terus terjaga sampai saat ini.

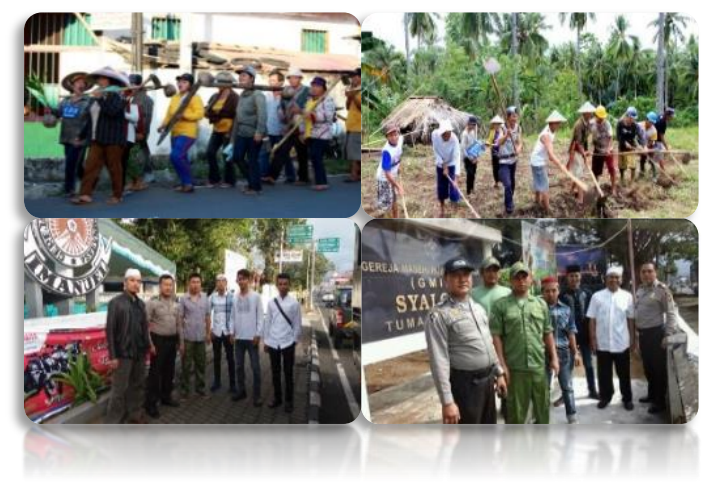

Gambar 2. Praktik Mapalus dalam Kehidupan Konkret

Masyarakat

Nilai Mapalus begitu kental dalam kehidupan sehari-hari, misalnya semangat saling menolong, berkumpul bersama dalam kerukunan-kerukunan marga dan kerukuan sosial lainnya. Mapalus adalah sebuah sistem nilai kehidupan masyarakat yang teraktualisasi dalam berbagai aspek kehidupan manusia sebagai aktualiasi hakikat manusia sebagai makhluk kerja. Nilai Mapalus inilah yang membuat orang Minahasa dan orang Tomohon pada khususnya menjadi begitu toleran terhadap orang-orang pendatang. Hal ini sejalan dengan pendapat Edward B. Tylor (1871) sebagaimana dikutip oleh (Munch \& Smelser, 1992) mengatakan bahwa budaya atau peradaban merupakan sebuah totalitas kompleks dari kepercayaan, seni, pengetahuan, adat-istiadat, hukum, dan kebiasaan-kebiasaan dan keterampilanketerampilan lain yang diperoleh manusia dalam hakikatnya sebagai bagian dari suatu masyarakat.

Mapalus juga merupakan suatu bentuk kearifan lokal masyarakat Sulawesi Utara khususnya Minahasa dan Tomohon. Mapalus sudah lama ada menjadi pegangan masyarakat dalam berpikir, bertindak dan berperilaku di tengah perbedaan masyarkaat.

\section{Semboyan Torang Samua Basudara}

Torang Samua Basudara adalah moto yang diprakarsai oleh tokoh nasional dari Sulut E. E. Mangindaan saat ia menjabat sebagai Gubernur Sulawesi Utara Propinsi. Moto Torang Samua Basudara sudah lama tumbuh dan berkembang sebagai nilai budaya masyarakat Sulawesi Utara. Moto ini dijalani dan diimplementasikan sepenuhnya oleh warga Nyiur Melambai/ Sulawesi Utara sehingga itu menjadi kearifan lokal yang mantap dan penawar bagi berbagai pihak potensi konflik, terutama konflik sosial pada tahun 1998-2000. Torang Samua Basudara telah menjadi slogan terkenal di Bumi Nyiur Melambai/Sulawesi Utara. Slogan ini adalah bukan hanya slogan kosong tetapi telah menjadi bagian dari kehidupan untuk orang Sulawesi Utara. Ini terbukti dari kondusifitas keamanan, harmoni, dan harmoni orang Sulawesi Utara. Prinsip Torang Samua Basudara menjadi identitas masyarakat Utara Sulawesi, yang perlahan-lahan menjadi nasional dan kepedulian internasional (Pangalila, Mantiri, \& Biringan, 2019).

Prinsip Torang Samua Basudara mengedepankan supremasi toleransi, yang merupakan fondasi paling mendasar untuk menciptakan harmoni dan harmoni dalam masyarakat. Komunitas Sulawesi Utara adalah masyarakat multidimensi yang terbentuk dari berbagai kepercayaan, suku, dan budaya yang berbeda. Manusia sebagai makhluk sosial memiliki pola, dan karakteristik yang berbeda sesuai dengan tingkat pendidikan, pergaulan, dan pengalaman mereka-berbagai pengalaman, pendidikan, budaya membentuk karakter setiap orang. Memaksakan selera kita pada orang lain tidak mungkin. Apa yang mungkin adalah bahwa setiap orang menyesuaikan diri dengan orang lain.

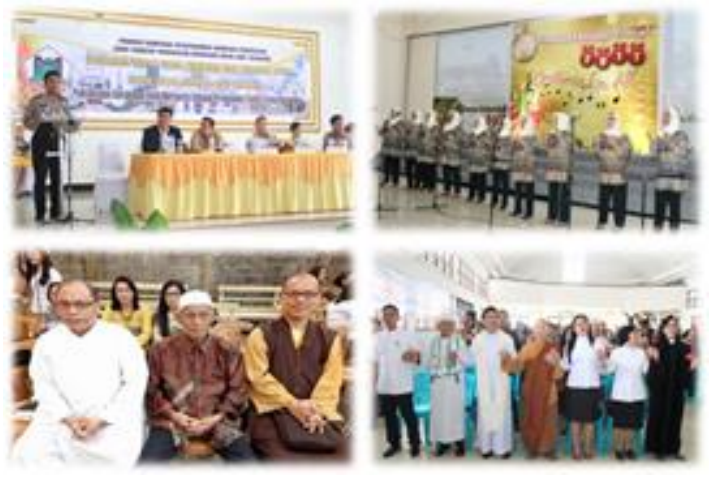

Gambar 3. Aktualisasi Semboyan Torang Samua Basudara

Nilai budaya Torang Samua Basudara sangat terpelihara dengan baik dan menjiwai kehidupan masyarakat kota Tomohon. Prinsip hidup inilah yang menjadi modal penting terciptanya sikap toleransi masyarakat kota Tomohon terhadap masyarakat pendatang yang berbeda agama dan suku.

Torang Samua Basudara menjadi hakikat dasar terjadinya toleransi dalam masyarakat yang beragama terutama dalam terciptanya kehidupan masyarakat yang rukun dan penuh keharmonisan. Masyarakat Sulawesi Utara adalah masyarakat multikultural yang dibentuk oleh adanya budaya, suku, kepercayaan dan agama yang berbeda. 


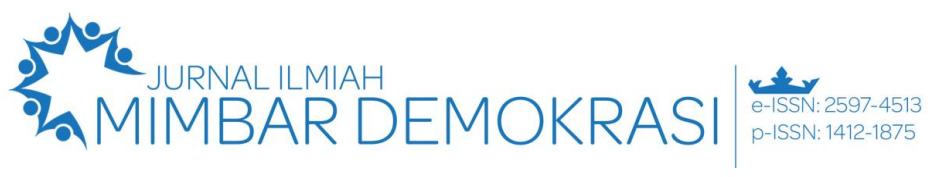

\section{Vol. 20 No. 1 Tahun 2020 | Hal. 55 - 64}

Perbedaan pengalaman dan pergaulan, sifat, coran dan tingkat Pendidikan merupakan hakikat paling dasar dari manusia sebagai makhluk sosial. Karakter setiap manusia terbentuk karena adanya perbedaan budaya, pendidikan dan pengalaman hidupnya. Peyesuaian diri dalam masyarakat adalah hal yang lebih bijaksana daripada memaksakan kehendak kita kepada orang lain. Pendapat ini sejalan dengan apa yang dikatakan oleh (Fallon, O'Keeffe, \& Sugai, 2012), yang mengatakan bahwa budaya berkaitan erat dengan kelompok individu, terutama tingkah laku verbal yang dipelajari secara turun temurun. Bagaimana kelompok tertentu membedakan dirinya dengan kelompok lain dan bagaimana individu itu bertindak dalam situasi yang spesifik. Artinya, "budaya" mencerminkan perkataan dan perilakuperilaku umum yang dipelajari dari konteks dan lingkungan budaya tertentu secara terus-menerus baik yang disebabkan oleh tindakan atau objek (stimulus) yang didefiniskan sebagai konteks tertentu.

Nilai budaya Torang Samua Basudara secara jelas menjadi alat pemersatu dan penjaga kerukunan hidup masyarakat Sulawesi Utara. Dengan kata lain Torang Samua Basudara telah menjadi modal sosial bagi masyarakat Sulawesi Utara dan Tomohon pada khususnya. Kenyataan ini sejalan dengan teori (Woolcock, 1998) tentang modal sosial yang menurutnya merupakan tingkatan sebuah integritas sosial dalam suatu komunitas atau masyarakat. Ia mengacu pada proses-proses antar orang yang membangun jejaring, norma-norma, dan social trust, dan memperlancar koordinasi dan kerja sama yang saling menguntungkan. Modal sosial merupakan sebuah resource atau sumber yang dihasilkan oleh adanya komunikasi dan interaksi di antara individu-individu yang merupakan anggota sebuah komunitas atau masyarakat. Kendati begitu, dalam kenyataannya pengukuran terhadap interaksi jarang dilibatkan dalam pengukuran modal sosial. Di sini terpeliharanya dan terciptanya atau kepercayaan antar warga suatu masyarakat merupakan hasil dari interaksi mereka setiap hari. Suatu interaksi bisa berlangsung dalam konteks individual ataupun lembaga (institusional) (Suharto, 2016). Dalam konteks individual, terjadinya sebuah interaksi yang melahirkan ikatan emosional sebagai akibat dari adanya hubungan yang mendalam antara individu dalam masyarkaat.

Dalam konteks kelembagaan, interaksi bisa muncul manakala tujan dan visi sebuah organisasi mempunyai persamaan dengan tujuan dan visi kelompok atau organisasi lainnya. Oleh karena itu, fakta berbicara bahwa ketika daerah-daerah lain di sekitar Sulawesi Utara (SULUT) terbakar emosi untuk berkonflik dengan mengatasnamakan agama, ternyata SULUT sulit disulut dan tetap hidup dalam kerukunan (Pangalila, Mantiri, \& Biringan, 2019).

Tabel 1.1 Deskripsi Nilai Budaya Si Tou Timou Tumou

Tou, Mapalus dan Torang Samua Basudara

\begin{tabular}{|c|c|c|}
\hline $\begin{array}{c}\text { NILAI } \\
\text { BUDAYA }\end{array}$ & DIMENSI & DESKRIPSI NILAI \\
\hline 1 & 2 & 4 \\
\hline $\begin{array}{c}\text { SiTou } \\
\text { Timou } \\
\text { Tumou Tou }\end{array}$ & $\begin{array}{ll}\text { 1. } & \text { Si tou (st) } \\
\text { 2. Si Tou Timon } \\
\text { (St2) } \\
\text { 3. Si Tou Timou Tou } \\
\text { (St3) } \\
\text { 4. SiTou Timon } \\
\text { Tumou Tou (St4) }\end{array}$ & 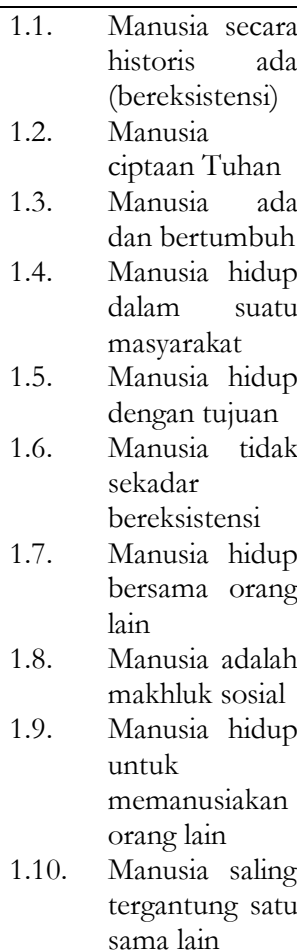 \\
\hline Mapalus & $\begin{array}{ll}\text { 1. Asas religius } \\
\text { 2. Asas } \\
\text { kekeluargaan } \\
\text { 3. Asas } \\
\text { musyawarah } \\
\text { dan mufakat } \\
\text { 4. Asas kerja } \\
\text { bersama } \\
\text { 5. Asas persatuan } \\
\text { dan kesatuan. }\end{array}$ & 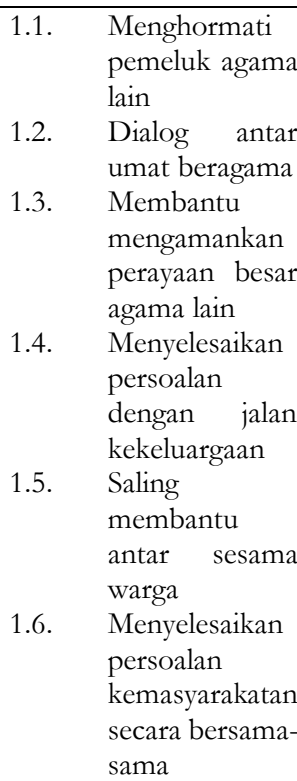 \\
\hline
\end{tabular}




\begin{tabular}{|c|c|c|c|}
\hline & & $\begin{array}{l}1.7 . \\
1.8 . \\
1.9 .\end{array}$ & $\begin{array}{l}\text { Bersama-sama } \\
\text { menciptakan } \\
\text { kerukunan } \\
\text { antar warga } \\
\text { Bergaul tanpa } \\
\text { memandang } \\
\text { latar belakang } \\
\text { suku, agama, } \\
\text { bahasa } \\
\text { Tanggung } \\
\text { jawab bersama } \\
\text { dalam menjaga } \\
\text { persatuan dan } \\
\text { kesatuan }\end{array}$ \\
\hline $\begin{array}{c}\text { Torang } \\
\text { Samua } \\
\text { Basudara }\end{array}$ & $\begin{array}{l}\text { 1. The way of life } \\
\text { (cara dan } \\
\text { pandangan } \\
\text { hidup) } \\
\text { 2. Menjunjung } \\
\text { tinggi rasa } \\
\text { toleransi } \\
\text { 3. Rasa hormat } \\
\text { kepada orang } \\
\text { tanpa } \\
\text { memandang ras, } \\
\text { agama dan } \\
\text { keyakinan } \\
\text { 4. Siap membantu } \\
\text { sesama tanpa } \\
\text { memandang } \\
\text { latar belakang. } \\
\text { 5. Mengedepankan } \\
\text { demokrasi }\end{array}$ & $\begin{array}{l}1.1 . \\
1.2 . \\
1.3 . \\
1.4 . \\
1.5 . \\
1.6 . \\
1.7 .\end{array}$ & $\begin{array}{l}\text { Sesama adalah } \\
\text { saudara } \\
\text { Manusia sama } \\
\text { di hadapan } \\
\text { Tuhan } \\
\text { Menghargai } \\
\text { orang lain } \\
\text { Menghargai } \\
\text { pemeluk agama } \\
\text { lain } \\
\text { Bergaul degan } \\
\text { siapa saja } \\
\text { Menghormati } \\
\text { orang yang } \\
\text { beda agama } \\
\text { dengan kita } \\
\text { Menghormati } \\
\text { orang yang } \\
\text { berasal dari } \\
\text { latar belakang } \\
\text { yang berbeda } \\
\text { dengan kita } \\
\text { Membantu } \\
\text { orang yang } \\
\text { mengalami } \\
\text { kesulitan } \\
\text { Saling tolong } \\
\text { menolong } \\
\text { Menyelesaikan } \\
\text { masalah secara } \\
\text { bersama-sama } \\
\text { Dialog antar } \\
\text { umat beragama }\end{array}$ \\
\hline
\end{tabular}

(Pangalila, 2013)

\section{Simpulan}

Nilai budaya Si Ton Timon Tumon Ton, Mapalus dan Torang Samua Basudara yang merupakan kearifan lokal masyarakat Sulawesi Utara sangat relevan untuk dijadikan model pendidikan Tolerani. Si Tou Timou Tumou Tou terwujud dalam sikap saling menghormati dan saling mengasihi. Mapalus terwujud dalam sikap saling membantu tanpa memandang perbedaan suku, agama, dan etnis. Torang Samua Basudara terlihat secara konkrit lewat sikap tidak membeda-bedakan di tengah masyarakat. Ketiga nilai budaya tersebut telah terbukti bisa menjaga keharmonisan dan kerukunan di Sulawesi Utara secara khusus di kota Tomohon.

\section{Ucapan Terima Kasih}

Terima kasih peneliti sampaikan kepada Direktorat Riset dan Pengabdian Kepada Masyarakat Kementerian Riset Teknologi dan Pendikan Tinggi yang sudah membiayai penelitian ini dan semua pihak yang telah terlibat.

\section{Referensi}

DM, H., \& Rijal, M. (2018). Pembinaaan Toleransi Antar Umat Beragama Perspektif Pendidikan Agama Islam Bagi Remaja Kota Kendari. Al-Irzah: Jurnal Hasil-Hasil Penelitian, 13(2), 224. https://doi.org/10.31332/ai.v13i2.1051

Endang, B. (2012). Mengembangkan Sikap Toleransi dan Kebersamaan di Kalangan Siswa. Jumal Visi Ilmu Pendidikan, 1(2), 89104.

Fallon, L. M., O'Keeffe, B. V, \& Sugai, G. (2012). Consideration of culture and context in school-wide positive behavior support: A review of current literature. Journal of Positive Behavior Interventions, 14(4), 209-219. Retrieved from http://pbi.sagepub.com/content/14/4/20 $9[03$

Geertz, C. (1975). Common sense as a cultural system. The Antioch Review, 33(1), 5-26.

Juwita, W., Salim, A., \& Winarno, W. (2018). Students' Tolerance Behavior in ReligiousBased Primary School: Gender Perspective. International Journal of Educational Research Review, 3(3), 51-58. https://doi.org/10.24331/ijere.426255

Khalikin, A., \& Fathuri. (2016). Toleransi Beragama di Daerah rawan Konflik. In A. Khalikin \& Fathuri (Eds.), Puslitbang Kebidupan Keagamaan Badan Litbang dan Diklat Kementerian Agama RI. Jakarta: Kementerian Agama RI Badan Litbang dan Diklat Puslitbang Kehidupan Keagamaan.

Latief, Y. (2017). Negara Paripurna: Historisitas, Rasionalisme, dan Aktualisasi Pancasila (6th ed.). Jakarta: Gramedia.

Marfai, M. A. (2012). Pengantar etika lingkungan dan Kearifan lokal. Yogyakarta: Gadjah Mada University Press.

Moleong, L. J. (2011). Metodologi Penelitian 


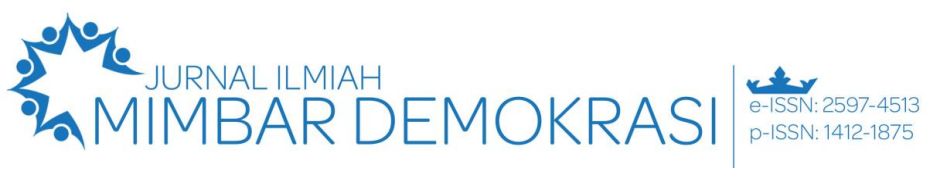

\section{Vol. 20 No. 1 Tahun 2020 | Hal. 55 - 64}

Kualitatif. Bandung: Remaja Rosdakarya.

Munch, R., \& Smelser, N. J. (1992). Theory of Culture. California: University of California Press.

Nasikun, J. (2011). Sistem sosial Indonesia. Yogyakarta: Universitas Gajah Mada Press.

Nugroho, P. (2018). Internalization of Tolerance Values in Islamic Education. Jurnal Pendidikan Islam, 12(51), 197-228. Retrieved from

http://journal.walisongo.ac.id/index.php/ nadwa

Pangalila, T. (2013). Pengarub internalisasi nilai budaya Si Tou Timou Tumou Tou, Mapalus dan Torang Samua Basudara Dalam Pembelajaran PKn Terhadap Peningkatan Sikap Toleransi Siswa: Penelitian Survey Terhadap Siswa SMA di Kota Tomohon-Sulawesi Utara. Universitas Pendidikan Indonesia, Bandung.

Pangalila, T. (2018). Toleransi dalam Keberagaman Masyarakat Lokal: Studi Fenomenologis Hubungan antar Agama dan Etnis pada Masyarakat Kota Tomohon Sulawesi Utara. Universitas Merdeka Malang.

Pangalila, T., \& Mantiri, J. (2019). The role of Tomohon society's local wisdom in developing tolerance attitudes. International Journal of Engineering and Advanced Technology, 8(5), 366-372. https://doi.org/10.35940/ijeat.E1052.058 5C19

Pangalila, T., Mantiri, J., \& Biringan, J. (2019). Nilai Moral yang Terkandung dalam Semboyan Torang Samua Basudara Sebagai Sumber Toleransi. Jurnal Moral Kemasyarakatan, 3(2), 71-77. https://doi.org/http://dx.doi.org/ $10.21067 / \mathrm{jmk}$

Pangalila, T., Mantiri, J., \& Umar, M. (2019). The Role of Mapalus Local Wisdom in Building the Tolerant Attitudes of the Tomohon City Community. In 2nd International Conference on Social Science (ICSS 2019) (Vol. 363, pp. 711-714). At. https://doi.org/10.2991/icss-19.2019.101

Pangalila, T., Ngarawula, B., \& Sadhana, K. (2018). Tolerance behavior among society in city of Tomohon, North Sulawesi. International Journal of Humanities and Social
Science Research, 4(4), 46-49. Retrieved from http://www.socialsciencejournal.in/archiv es/2018/vol4/issue4

Pangalila, T., Ngarawula, B., Sadhana, K., Lonto, A. L., \& Pasandaran, S. (2018). Local Wisdom Si Tou Timou Tumou Tou In Forming Tolerance of Tomohon City People of North Sulawesi. In 1 st International Conference on Social Sciences (ICSS 2018). Atlantis Press.

Raihani. (2011). A whole-school approach: A proposal for education for tolerance in Indonesia. Theory and Research in Education, 9(1), 23-39. https://doi.org/10.1177/14778785103948 06

Salaki, R. J. (2014). Membangun karakter generasi muda melalui budaya mapalus suku minahasa. Jurnal Studi Sosial, Vol.1(November), 47-52. https://doi.org/10.13140/RG.2.2.35305.6 0004

Suharto, E. (2016). Modal Sosial dan Kebijakan Publik. Retrieved 14 January 2017, from www.policy.hu/suharto/.../Modal Sosial dan Kebijakan Sosial.pdf

Sutiawan, I. (2019). Sepanjang 2019, Imparsial Sebut 31 Kasus Intoleransi di Indonesia. Retrieved 14 June 2020, from https://www.gatra.com/detail/news/4571 57/politik/sepanjang-2019-imparsialsebut-31-kasus-intoleransi-di-indonesia

Sutrisno, M., \& Putranto, H. (2005). Teori-teori kebudayaan. Kanisius.

Syahid, A., \& Daulay, M. Z. (2002). Riuh di beranda satu: peta kerukunan umat beragama di Indonesia. Jakarta: Departemen Agama RI bekerjasama dengan Badan Litbang Agama dan Diklat Keagamaan serta Puslitbang Kehidupan Beragama.

Tilaar, H. A. R. (1998). Si Tou Timou Tumou Tou: suatu konsep pembangunan sumber daya manusia dalam rangka pembangunan Minahasa menuju tinggal landas pembangunan. Manado. Retrieved from http://perpustakaan.bappenas.go.id/lontar / file?file=digital/19169-[_Konten_]Konten 200.pdf

Turang, J. (1984). Pembangunan Daerah Minahasa 
dengan Pertanian Inti Sistem Mapalus. Manado: Yayasan Mapalus.

Turang, T. I., Suman, A., Mandang, J., \& Soemarno. (2012). Kajian Peran Mapalus dalam Pemberdayaan Masyarakat di Kota Tomohon. Wacana, 15(4), 1-7. Retrieved from https://wacana.ub.ac.id/index.php/wacan a/article/view/263/221

Umbas, V. (2011). Dynamic of Mapalus. Researcher of ICRES.

Waruwu, D., \& Pramono, J. (2018). Pemanfaatan Kawasan Puja Mandala sebagai Model Toleransi di Provinsi Bali. Jurnal Pendidikan Kewarganegaraan, 22(2), 9-15. Retrieved from civicus.upi.edu

Wirutomo, P. (2011). Sistem sosial Indonesia. Jakarta: Penerbit Universitas Indonesia.

Woolcock, M. (1998). ocial Capital and Economic Development: Toward a Theoretical Synthesis and Policy Framework. Retrieved from http://www.socialcapitalgateway.org/cont ent/paper/woolcock-m-1998-socialcapital-and-economic-developmenttoward-theoretical-synthesis-a 